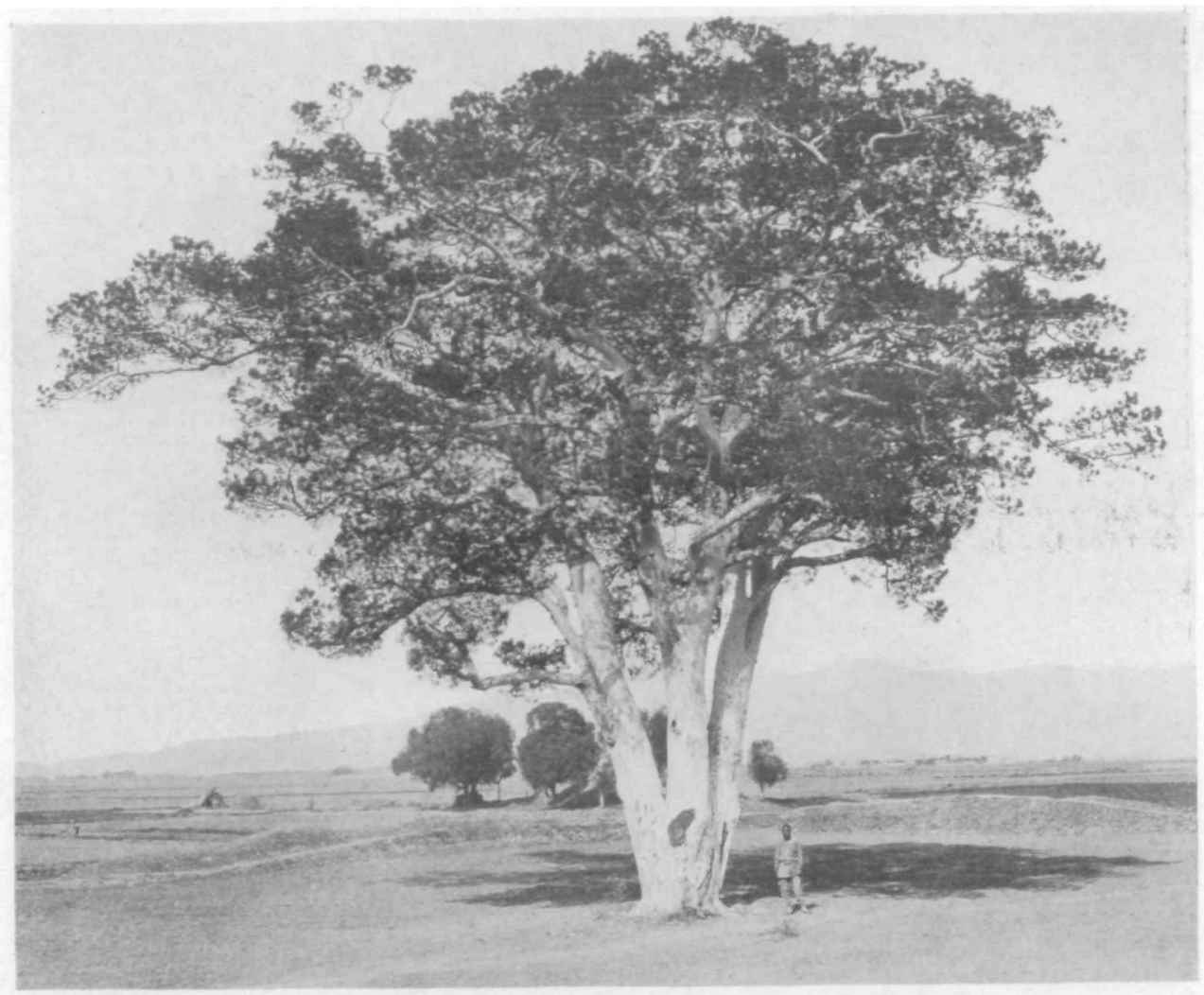

USUAL GROWTH HABIT OF WHITE-BARKED PINE

A typical specimen in appearance, but larger than usual. The tree stands on what was doubtless once a grave or the site of a small temple; remains of the grave or buildings have long since been obliterated by farmers. This beautiful pine has been introduced to the United States, but appears to lose its white color if it is grown in a moist locality. Photograph by D. F. Higgins. (Fig. 5.)

\title{
- THE WHITE-BARKED PINE
}

\author{
D. F. Higgins, Peking, China
}

I $\mathrm{N}$ ONE of my first trips sight-seeing around the city of Peking, when almost anything new and strange was taken quite as a matter of course, I remember seeing in the enclosure of "Coal Hill" some pine trees whose snow-white bark shone out from their green foliage. I wondered at the time why it was that the Chinese whitewashed their pine trees. Later, however, in excursions into the country, . I found that my whitewashed pines were not whitewashed, but that they had a white bark.

I became interested in this curious tree, and later, largely through the inspiring acquaintance formed with Frank N. Meyer, Agricultural Explorer of the United States Department of Agriculture, I took a number of photographs which may be of interest to the readers of the JOURNAL OF HEREDITY.

The tree (Pinus Bungeana) is most striking and noble in appearance, and 